\title{
Evaluation of Beef Manure Production and Bedding Removal Time in Bedded Pack Barn
}

\author{
Jo, Hyeon-Soo \\ Laboratory of Environmental Economics, Department of Agricultural and Resource Economics, \\ Faculty of Agriculture, Kyushu University | Dept. of Animal Biosystems Science, Chungnam \\ National University
}

\section{Lee, Seung-Hun}

Laboratory of Environmental Economics, Department of Agricultural and Resource Economics, Faculty of Agriculture, Kyushu University | Dept. of Animal Biosystems Science, Chungnam National University

Lee, Jae-Hee

Laboratory of Environmental Economics, Department of Agricultural and Resource Economics, Faculty of Agriculture, Kyushu University | Dept. of Animal Biosystems Science, Chungnam National University

\section{Lee, Myung-Gyu}

Laboratory of Environmental Economics, Department of Agricultural and Resource Economics, Faculty of Agriculture, Kyushu University | Department of Environmental Engineering, Sangji University

他

https://doi.org/10.5109/1801786

出版情報：九州大学大学院農学研究院紀要. 62 (1)，pp.213-216，2017-02-24. Faculty of Agriculture, Kyushu University

バージョン :

権利関係 : 


\title{
Evaluation of Beef Manure Production and Bedding Removal Time in Bedded Pack Barn
}

\author{
Hyeon-Soo JO ${ }^{1}$, Seung-Hun LEE ${ }^{1}$, Jae-Hee LEE ${ }^{1}$, Myung-Gyu LEE ${ }^{2}$, Mitsuyasu YABE \\ and Heekwon $\mathrm{AHN}^{1 *}$
}

\author{
Laboratory of Environmental Economics, Department of Agricultural and Resource Economics, \\ Faculty of Agriculture, Kyushu University, Fukuoka 812-8581, Japan \\ (Received October 20, 2016 and accepted November 4, 2016)
}

\begin{abstract}
The current study was conducted to clarify the amount of manure production from Korean native beef cattle (Hanwoo) raised in bedded pack barn and the suitable bedding replacement time. Total forty heads of Hanwoo (about $412 \mathrm{~kg}$ body weight) were raised in five pens ( $7.5 \mathrm{~m}^{2}$ per head) for 76 days. Average daily manure production without bedding was $13.4 \mathrm{~kg} / \mathrm{head}$. The amount of daily manure production including the bedding was $14.9 \mathrm{~kg} / \mathrm{head}$, which is $14 \%$ lesser than conventional S. Korean Hanwoo manure production unit $(17.3 \mathrm{~kg} / \mathrm{head})$. During the first 30 days, moisture content of sawdust beddings were considerably increased up to $89 \%$ of water holding capacity (WHC) of sawdust. It maintained a very stable level between 30 to 50 days. Academically, 30 days after adding fresh bedding seems to be appropriate replacement time based on WHC. Whereas, from a practical standpoint, maximum 50 days should be acceptable by considering several other factors, such as the expense of purchasing bedding material, the cleanliness of the feeding environment, and the availability of manure treatment.
\end{abstract}

Key words: Beef manure, Bedding material, Bedding replacement, Water holding capacity, Sawdust

\section{INTRODUCTION}

Livestock manure, after appropriate biological and physiochemical treatment, can be utilized as a fertilizer source necessary for crop growth and energy sources, such as biogas and solid fuel (Manyi-Loh et al., 2013; Mazeika et al., 2016; De-Vries et al., 2012). On the other hand, if managed inappropriately, livestock manure can act as sources of soil and water pollution and odor generation. Therefore, it is most important to develop and employ environmentally friendly manure management technology to improve rural residential environment and negative image of stock raising industries (Appels et al., 2011; Kim et al., 2015).

Until 2010, swine manure used to receive more attention than cattle manure. Thus, swine manure-centered treatment and management were performed dominantly. Then, as the swine manure treatment technology became stable and people's awareness toward environment changed, civil complaints regarding cattle manure surged and cattle manure-related regulations became strict (Kim et al., 2016). In this situation, to properly manage cattle manure, it has become necessary to secure more accurate data on physiochemical properties and production units of manure. Though a lot of studies have been conducted to identify the cattle manure production units and the physiochemical properties of cattle manure, these studies just stayed within the limits of presenting manure production unit evaluation based on metabolism cage without reflecting the characteristics of bedded pack barn. If such data are used to estimate manure amount, which is collected in the mixture with bedding materials from bedded pack barns every $2 \sim 3$

\footnotetext{
Dept. of Animal Biosystems Science, Chungnam National University, Daejeon 305-764, Korea;

2 Dept. of Environmental Engineering, Sangji University, Wonju, Gangwon 220-702, Korea;

* Corresponding author (E-mail: hkahn@cnu.ac.kr)
}

months, it becomes difficult to gain any realistic value.

Over almost $93 \%$ of South Korean beef and dairy cattle farms use bedding materials to collect manure (Kim et al., 2016). Various kinds of bedding materials are utilized depending upon livestock species and barn types. Of them, rice hulls, expanded rice hull and sawdust are the major bedding materials used frequently. They are selectively utilized in cow sheds considering livestock feeding management convenience and price; if necessary, they are even mixed. Sawdust is one of the most broadly used bedding materials in South Korean bedded pack barns. In 2014, sawdust was traded at USD 210 per ton. According to the guidelines for shed floor management of National Institute of Animal Science (Kang et al., 1995), it is ideal to change the sawdust bedding of cowsheds every 38 days or 9.6 times a year if $5 \mathrm{~cm}$ thickness of bedding is placed. The sawdust changing cost of each time is about USD $26(124 \mathrm{~kg})$ per head of Korean native cattle for breeding. It costs about USD 250 per head a year. This high cost of sawdust works as a critical factor in farming households' decision on when to change the sawdust.

In terms of animal welfare and shed environmental management, it is also critical to change bedding materials at an appropriate point of time (Tucker and Weary, 2004; Fregonesi et al., 2007). Overused bedding materials can have a negative effect on livestock raising environment by causing vermination and diseases, undermining productivity directly. Moreover, overused bedding materials carry excessive moisture to disturb normal composting process and cause environmental pollution due to foul smell and low-quality compost (Das and Keener, 1997; Ahn et al., 2008a).

To address the aforementioned problems, the current study has evaluated and re-estimated the manure amount produced from Korean native beef cattle raised at bedded pack barns. An appropriate bedding material change cycle has also been proposed after considering 
the moist absorption characteristics of bedding materials and manure mixture as well as the sawdust cost.

\section{MATERIALS AND METHODS}

The amount of Korean native beef cattle manure production in bedded pack barns and its physiochemical characteristics were evaluated for 76 days. To maintain identical experimental conditions, 40 cows were raised with a stocking density of $7.5 \mathrm{~m}^{2}$ per head in a cowshed built according to the standard design suggested by KNACF (2008). Total mixed ration (TMR) was fed twice a day (10:00 am, 6:00 pm) with free water access. Sawdust was used for bedding. A forklift truck and skid loader were used to bring in commercial sawdust in units of $500 \mathrm{~kg}$. After completing the $1^{\text {st }}$ round of sawdust take-in, it was evenly distributed in $5 \mathrm{~cm}$ thickness. Then, 40 cows were placed in the 5 pens, as shown in Table 2. Sampling was done at 5 or more sampling points in every cow pen. In order to ensure the homogeneity of the collected samples, secondary classification was performed according to the VDI4630 (2006). The samples were kept under refrigeration at $4^{\circ} \mathrm{C}$ for characteristic analysis. A structure with $90 \mathrm{~cm}$ height, $180 \mathrm{~cm}$ width and $90 \mathrm{~cm}$ length was built in this experiment to weigh the manure mixed with bedding material after experiment termination by utilizing the skid loader and pallet scale ( 2 ton $\pm 1 \mathrm{~kg}$ ). The properties of sawdust used in this study are shown in Table 1.

Manure sample collected from each cow pen was dried at $105^{\circ} \mathrm{C}$ for 24 hours and its moisture content was measured. Then it was burned to ash at $550^{\circ} \mathrm{C}$ for 8 hours to measure volatile solid content (USCC, 2002).

Water holding capacity (WHC) was analyzed by

Table 1. Characteristics of sawdust bedding

\begin{tabular}{cc}
\hline Items & Sawdust \\
\hline Moisture contents (\%, w.b.) & $6.5 \pm 0.2$ \\
Volatile solids (\%, d.b.) & $98.6 \pm 0.4$ \\
Water holding capacity (\%, w.b.) & $80.2 \pm 0.6$ \\
Bulk density $\left(\mathrm{kg} / \mathrm{m}^{3}\right)$ & $250 \pm 3.0$ \\
\hline & (mean \pm S.D., $\mathrm{n}=6)$
\end{tabular}

modifying the existing method of Hilgard (Ahn et al., 2008a; Mabuhay et al., 2003). In a typical experiment, about $100 \mathrm{~g}$ of sample was placed in a beaker and weighed. Distilled water was added enough to barely cover the sample in the beaker and left at room temperature for 24 hours. The liquid was filtered with a funnel and filter paper (pore size $2.5 \mu \mathrm{l}$ ) to the maximum possible extent. Next, the filter paper was covered with a beaker turned upside down and placed on the screen. To minimize moisture loss through evaporation, they were kept within a closed space with little temperature change for 24 hours. After 24 hours, the sample containing beakers were weighed. The WHC was calculated as in the equation (1);

$$
\operatorname{WHC}(\%)=\frac{\left(W_{S}-M\right)+M C_{i} \times M}{W_{S}}
$$

$\mathrm{W}_{\mathrm{s}}$ : Weight of saturated sample

$\mathrm{MC}_{\mathrm{i}}$ : Initial moisture content of sample

M: Mass of the wet sample

Bulk density was measured by putting the sample in 1L mess cylinder and weighing it. In this process, to reduce the empty spaces inside sample, the sample was dropped the same number of times (3-5 times) from the same height (approximately. $10 \mathrm{~cm}$ ) for measurement (Ahn et al., 2008b). The bulk density calculation was done using equation (2);

$$
\text { Bulk density }(\mathrm{g} / \mathrm{mL})=\frac{\text { Sample weight }(\mathrm{g})}{\text { Volume of the cylinder }(\mathrm{mL})} \cdots
$$

\section{RESULTS AND DISCUSSION}

Table 2 shows the body weights of cows used in this experiment along with each cow pen area, cattle headcount and feed intake. TMR was provided twice a day at 8:00 am and 6:00 pm. For the 76 days of experiment, $1.9 \%$ (dry matter basis) of daily average weight or a total of $585 \mathrm{~kg}$ of TMR was fed. An average of $44.3 \mathrm{~kg}$ of weight gain was observed.

Table 3 shows used sawdust volume, manure production volume and weight of sawdust bedding materialmixed manure. The average amount of sawdust used per cow was $108 \mathrm{~kg}$ and as bedding material was $14.4 \mathrm{~kg}$

\begin{tabular}{|c|c|c|c|c|c|c|}
\hline \multicolumn{3}{|c|}{ Pen } & \multicolumn{3}{|c|}{ Body weight (kg) } & \multirow{2}{*}{$\begin{array}{c}\text { Feed intake } \\
\left(\mathrm{DM}^{\dagger} \mathrm{kg} / \text { head·day }\right)\end{array}$} \\
\hline No. & head & Area $\left(\mathrm{m}^{2}\right)$ & Mean & Initial & Final & \\
\hline 1 & 10 & 75 & $397 \pm 36$ & 377 & 417 & $6.7 \pm 1.4$ \\
\hline 2 & 10 & 75 & $403 \pm 33$ & 383 & 431 & $7.7 \pm 1.2$ \\
\hline 3 & 7 & 50 & $425 \pm 17$ & 408 & 435 & $8 \pm 0.8$ \\
\hline 4 & 3 & 25 & $426 \pm 3$ & 399 & 460 & $8.9 \pm 1.4$ \\
\hline 5 & 10 & 75 & $412 \pm 20$ & 392 & 438 & $7.1 \pm 0.8$ \\
\hline Average & & $7.5 \mathrm{~m}^{2} /$ head & $412 \pm 12$ & $392 \pm 11$ & $436 \pm 14$ & $7.7 \pm 0.7$ \\
\hline
\end{tabular}

Table 2. Arrangement of cattle and their performance (weight gain and feed intake) 
per $\mathrm{m}^{2}$. The net manure production amount excluding the sawdust bedding material was $136 \mathrm{~kg}$ per $\mathrm{m}^{2}$, which was approximately 9.4 times higher than that with sawdust.

Excluding the bedding material, daily production of net manure per head was $13.4 \mathrm{~kg}$, whereas, including the bedding material, the daily manure production per head was $14.9 \mathrm{~kg}$, which is $14 \%$ less than the conventional S. Korea Hanwoo manure production unit (17.3 kg) evaluated based on metabolism cage (KRDA, 2009).

The changes in properties of sawdust bedding material and Korean cattle manure mixture with time have been displayed in Figures 1 and 2. The moisture contents of the bedding material and manure mixture showed a rapid increase until Day 30 and the moisture content of sawdust at this point steeply rose up to a maximum of $89 \%$ of WHC.

From Day 30 of the experiment to its completion, the Korean cattle manure moisture content showed a gradual increase (Fig. 1). This is deemed because the sawdust bedding was fully saturated then it could not absorb more moisture.

Volatile solid content was $98.5 \%$ on the day of sawdust carry-in, representing the original sawdust property. However, around Day 30, the level reduced to 85.5\%. After Day 30, the decrease in the volatile solid was remarkably slow and remained around 83.3\% until the last day (Fig. 2).

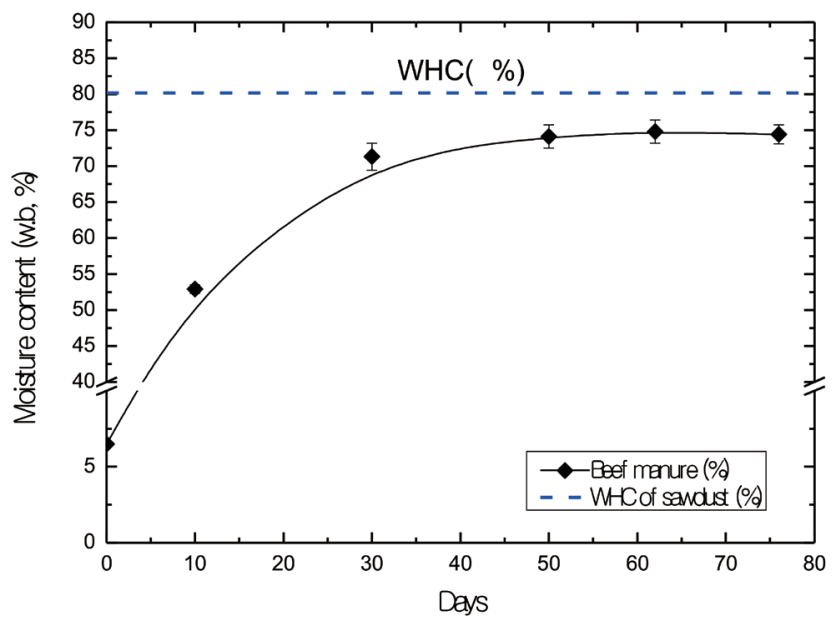

Fig. 1. Variation of moisture content of beef manure and sawdust bedding mixture.

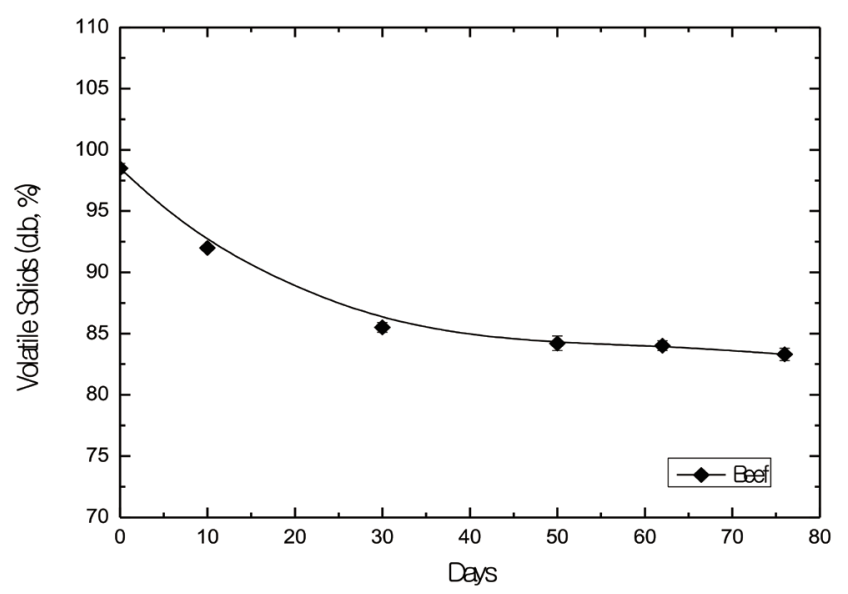

Fig. 2. Variation of volatile solids content of beef manure and sawdust bedding mixture.

The optimal moisture content for normal composting is approximately 50 60\% (Liang et al., 2003). If this level is exceeded, moisture fills in the voids to foster an anaerobic condition, disturbing efficient composting and causing odor (Ahn et al., 2008a). Thus, for stable manure treatment and livestock feeding and management control, it is desirable to change sawdust within 10 30 days as much as possible. However, given the sawdust cost, it is not easy to actually follow this sawdust-replacement schedule. If manure treatment cost is considered, the sawdust bedding material change period may be extended up to the maximum possible term where manure treatment problems caused by increased moisture content can still be under control. By considering the aforementioned factors comprehensively, a 50-day sawdust-changing schedule is deemed practical.

\section{CONCLUSION}

To conclude, manure amount produced by Korean native cattle raised in bedded pack barns was evaluated and an appropriate bedding material change cycle was presented by considering the moisture absorption characteristics of bedding materials and sawdust purchasing cost.

In the sawdust bedded pack barns with $7.5 \mathrm{~m}^{2} /$ head density, the daily net manure production amount was

Table 3. Mass of sawdust initially added and manure accumulated in barns during the experiment period

\begin{tabular}{|c|c|c|c|c|c|c|c|c|c|}
\hline \multirow{2}{*}{ No. } & \multicolumn{3}{|c|}{ Input sawdust } & \multicolumn{3}{|c|}{ Manure and bedding } & \multicolumn{3}{|c|}{ Manure only } \\
\hline & $\mathrm{kg}$ & $\mathrm{kg} / \mathrm{m}^{2}$ & kg/head & $\mathrm{kg}$ & $\mathrm{kg} / \mathrm{m}^{2}$ & $\mathrm{~kg} / \mathrm{head} \cdot \mathrm{day}$ & $\mathrm{kg}$ & $\mathrm{kg} / \mathrm{m}^{2}$ & $\mathrm{~kg} / \mathrm{head} \cdot \mathrm{day}$ \\
\hline 1 & 1,443 & 19.2 & 144 & 9,748 & 130.0 & 12.8 & 8,305 & 111 & 10.9 \\
\hline 2 & 1,060 & 14.1 & 106 & 9,616 & 128.2 & 12.7 & 8,556 & 114 & 11.3 \\
\hline 3 & 580 & 11.6 & 83 & 7,614 & 152.3 & 14.3 & 7,034 & 94 & 13.2 \\
\hline 4 & 456 & 18.2 & 152 & 3,229 & 129.2 & 14.2 & 2,773 & 111 & 12.2 \\
\hline 5 & 794 & 10.6 & 79 & 14,937 & 199.2 & 19.7 & 14,143 & 189 & 18.6 \\
\hline & Iean & 14.4 & 108 & - & 150.5 & 14.9 & - & 136 & 13.4 \\
\hline
\end{tabular}


$13.4 \mathrm{~kg} / \mathrm{head}$ and the manure and sawdust bedding material mixture production was $14.9 \mathrm{~kg} / \mathrm{head}$, showing a $14 \%$ lesser amount than the existing S. Korean beef cattle daily manure production unit $(17.3 \mathrm{~kg} / \mathrm{head})$.

In around 30 days after sawdust bedding material carry-in, the moisture content of manure mixture including sawdust bedding material soared up to $89 \%$ of sawdust WHC. However, after Day 30, the moisture content increase was noticeably slow. If sawdust bedding material change cycle is estimated by considering the livestock feeding management and manure treatment aspects, 30 days after initial use is ideal. However, the sawdust bedding material change cycle may be extended to a maximum possible period of 50 days where expected manure treatment problems are still under control in order to minimize manure treatment cost. This is because the sawdust bedding material's moisture content increase is markedly slow in this 50-day period.

The present study showed manure production unit and physiochemical characteristics of beef cattle raised in bedded pack barn and such findings are expected to be useful as the basic material necessary for designing and operating individual farm manure treatment facilities and centralized livestock manure treatment plant facilities.

\section{ACKNOWLEDGEMENTS}

This research was funded by the Rural Development Administration (Project No. PJ11694012015) Republic of Korea. However we received an enormous help from Prof. Myung- Gyu Lee, Sangji University during our study. In particular, a special thanks to Prof. Yabe, Kyushu University in Japan for his collaboration in the experimental design and interpretation of results and help to write research paper in this study.

\section{REFERENCES}

Ahn, H.K., T.L. Richard, T.D. Glanville 2008a Optimum moisture levels for biodegradation of mortality composting envelope materials. Waste Management, 28: 1411-1416

Ahn, H.K., T.L. Richard, T.D. Glanville 2008b Laboratory determination of compost physical parameters for modeling of airflow characteristics. Waste Management, 28: 660-670

Appels, L., J. Lauwers, J. Degrève, L. Helsen, B. Lievens, K. Willems, J. Van Impe, R. Dewil 2011 Anaerobic digestion in global bio-energy production: Potential and research challenges. Renewable and Sustainable Energy Review, 15:
4295-4301

Das, K. and H. Keener 1997 Moisture effects on compaction and permeability in composts. Joumal of Environmental Engineering 123: 275-281

De-Vries, J.W., T.M.W.J., Vinken, L. Hamelin, I.J.M., De-Boer 2012 Comparing environmental consequences of anaerobic monoand co-digestion of pig manure to produce bio-energy - A life cycle perspective. Bioresource Technology, 125: 239-248

Fregonesi, J.A., D.M. Veira, M.A.G. Von-Keyserlingk, D.M. Weary 2007 Effects of bedding quality on lying behavior of dairy cows. Journal of Dairy Science, 90: 5468-5472

Kang H.S., S.K. Hong, W.M. Cho, B.H. Paek, C.H. Park, D.S. Lee 1995 Effects of sawdust and rice hulls litter on the waste management of Hanwoo (Korean Native Cattle). Journal of livestock housing and environment, 1: 1-8

Kim, E.J. 2015 Effect of moisture content and leachate recirculation frequency on biogas production performance during solid-state anaerobic digestion of dairy manure. M.A. Thesis, Chungnam National University, Daejeon, Korea.

Kim, E.J., D.H. Lee, S.G. Won, H.K. Ahn 2016 Evaluation of optimum moisture content for composting of beef manure and bedding material mixtures using oxygen uptake measurement. Asian Australasian Journal of Animal Science, 29: 753758

KNACF 2008 Livestock housing standard plan. Korea National Agricultural Cooperative Federation

KRDA 2009 The study to re-establish the amount and major compositions of manure from livestock, GOVP-1200958504, Korea Rural Development Administration

Liang, C., K.C. Das, R.W. McClendon 2003 The influence of temperature and moisture contents regimes on the aerobic microbial activity of a biosolids composting blend. Bioresource Technology, 86: 131-137

Mabuhay, J. A., N. Nakagoshi and T. Horikoshi 2003 Microbial biomass and abundance after forest fire in pine forests in Japan. Ecological Research, 18: 431-441

Manyi-Loh, C.E., S.N. Mampheli, E.L. Meyer, A.I. Okoh, G. Makaka, M. Simon 2013 Microbial anaerobic digestion as an approach to the decontamination of animal wastes in pollution control and the generation of renewable energy. International Journal of Environmental Research and Public Health, 10: 4390-4417

Mazeika, R., G. Staugaitis, J. Baltrusaitis 2016 Engineered pelletized organo-mineral fertilizers (OMF) from poultry manure, diammonium phosphate and potassium chloride. ACS Sustainable Chemistry Engineering, 4: 2279-2285

Tucker, C.B., D.M. Weary 2004 Bedding on geotextile mattresses: How much is needed to improve cow comfort. Journal of Dairy Science, 87: 2889-2895

USCC 2002 TMECC 4.11-A: Test methods for the examination of composting and compost. US Composting Council; Ronkonkonma, NY, USA

VDI 4630. 2006 Fermentation of Organic Materials Characterization of the Substrate, Sampling, Collection of Material Data, Fermentation Tests, In "VDI Guideline 4630", Verein Deutscher Ingenieure, Düsseldorf, German 